\title{
Simple physiological indicators of young goats bred in extensive system
}

\author{
Laylson da Silva Borges • Fernanda Samara Barbosa Rocha
}

LS Borges (Corresponding author) - FSB Rocha

email: laylson_borges@hotmail.com

Centro de Ciências Agrárias, Universidade Federal do Piauí

(UFPI), Teresina, PI, Brazil.

Received: January 22, 2018 - Revised: February 06, 2018 • Accepted: February 06, 2018

\begin{abstract}
The aim of this study was to evaluate the influence of day shift on physiological variables of young goats bred in an extensive system. Ten females of undefined racial pattern were used, with a mean age of 5 months, distributed in a completely randomized design, with two treatments (morning and afternoon shift) and 10 replications per treatment. The environmental variables were collected through a digital thermo-hygrometer. Respiratory and heart rate, and rectal temperature were measured. During the experimental period the averages of the air temperature and relative humidity, and the black globe-humidity index (BGHI) were of $38.80{ }^{\circ} \mathrm{C}$, $25.76 \%$ and 78.11 , respectively. It was observed effect $(\mathrm{P}<0.05)$ of day shift on all physiological variables, with highest averages observed in the afternoon shift. The animals increased the respiratory and heart rate during the day periods to be able to maintain the rectal temperature within limits considered normal for this species.
\end{abstract}

Keywords: ambience, goat farming, physiological variables, thermal discomfort

\section{Introduction}

Goat breeding in Brazil is undergoing important changes over the years, showing growth in the market and obtaining relevant positions in the Brazilian agribusiness (Lima and Barbosa Filho 2013). However, majority of the animals are bred in subtropical and tropical climate conditions, and effects of air temperature and relative humidity on these conditions are obstacles to development, production and reproduction of these animals (Kawadata et al 2005).

Goats of undefined racial pattern stand out by their rusticity, besides being commonly exploited for meat production. Currently, around $93 \%$ of the goat herd, is in the Northeast region, with highlights for Bahia, Pernambuco, Piauí and Ceará, the four states corresponding to $77.7 \%$ of the national herd (IBGE 2016). It is emphasized that heat during the dry season is one of the main adversities in this geographical region, because it causes heat stress to the animals, inducing changes in the physiological functions that consequently cause a decline in productive performance. In this way, making use of adequate management, especially during this season, will allow greater profits for goat farming.

In this context, this research is justified as being an opportunity to know the influence that the day shift exercises on the physiological variables of young goats bred in an extensive system. It is worth mentioning that it is worrying that animals are bred in this system type, since they do not have access to covered facilities when under high air temperature and if the pasture does not have natural shade. Given the above, this study aimed to evaluate the influence of day shift on the physiological variables of young goats bred in an extensive system.

\section{Materials and Methods}

Our study was performed at Coroatá farm, located in the municipality of Eliseu Martins, Piauí state, semi-arid region of Northeast Brazil. This region is characterized by two distinct seasons, the rainy season (from January to June) and the dry season (July to December), with a maximum average annual temperature of $33.25{ }^{\circ} \mathrm{C}$ and a minimum of $20.93{ }^{\circ} \mathrm{C}$ and average annual rainfall of $878 \mathrm{~mm}$.

Ten females goats of undefined racial pattern, with an mean age of 5 months, were bred in an extensive system with native pasture. Mineral supplementation (common salt) and water were provided ad libitum. The animals were taken to the fold only for data collection and normal sanitary management. A pre-experimental period of 15 days was used, aiming, therefore, to adapt them to the management and data measurement.

The physiological variables studied were: respiratory rate (RR), heart rate (HR) and rectal temperature (RT). The observations were performed in the morning shift between 09:00 and 10:30 hours, and afternoon shift between 15:00 and 16:30 hours, daily, for 15 days, in the dry season. RR was obtained by direct observation of the left flank movements of the animals for one minute (breaths/min). HR was measured with the aid of a flexible stethoscope placed directly in the left 
thoracic region (beats/min). RT $\left({ }^{\circ} \mathrm{C}\right)$ was determined by introducing a veterinary clinical thermometer directly into the rectum of the animal for a period of two minutes.

A digital thermo-hygrometer (SKILL-TEC) was installed at a distance of two meters from the fold, in order to measure the air temperature $\left(\mathrm{TA},{ }^{\circ} \mathrm{C}\right.$ ) and relative humidity (UA, \%), and a black globe thermometer (TG, ${ }^{\circ} \mathrm{C}$ ). The measurement of these variables were performed at 9:00 and at 15:00 hours, during the whole experimental period, in the morning and afternoon shifts. The black globe-humidity index (BGHI) was determined based on TG and dew point temperature (Tdp), as calculated by Araújo et al (2016) according to formula:

$$
\mathrm{BGHI}=\mathrm{TG}+0.36 \times \mathrm{Tdp}+41.5
$$

where TG is black globe temperature $\left({ }^{\circ} \mathrm{C}\right)$, Tdp is dew point temperature $\left({ }^{\circ} \mathrm{C}\right)$ and 41.5 is a constant.

A completely randomized design was used, with two treatments, in which one treatment refers to the morning shift and the other to the afternoon shift, and 10 repetitions per treatment. The data obtained were statistically analyzed by $\mathrm{R}$ software (R, CORE TEAM 2016) and the means compared by Tukey test at the $5 \%$ probability level.

\section{Results and Discussion}

The analysis of variance revealed effect of day shift $(\mathrm{P}<0.05)$ for all environmental variables and BGHI. A significant increase $(\mathrm{P}<0.05)$ of $18.4 \%$ and $6.16 \%$ in the afternoon shift when compared to morning shift to TA and BGHI, respectively, were observed. However, for UA there was a significant reduction $(\mathrm{P}<0.05)$ of $32.5 \%$ in the afternoon shift in relation to morning shift (Figure 1). These values can be justified by higher incidence of solar radiation observed during afternoon shift, causing an increase in TA and BGHI and consequently a reduction in the UA in this shift.

It should be noted that the TA showed a thermal amplitude of $6.54{ }^{\circ} \mathrm{C}$, with an average of $42.07{ }^{\circ} \mathrm{C}$ in the afternoon shift, as mentioned previously, this average is allied to low UA $(20.76 \%)$ in this same day shift. According to Silva et al (2011), TA means in both shifts studied were higher than those considered within the thermal comfort zone for goats, which according to the aforementioned authors can vary between 20 and $30^{\circ} \mathrm{C}$.

BGHI averages were high in both day shifts, with values of 75.78 in the morning shift and 80.45 in the afternoon shift. The mean value found in afternoon shift indicates a possible alert situation for the animals (Souza et al 2002), and this caused them to increase the respiratory rate to maintain rectal temperature within limits considered normal for the species. Corroborating with this statement, Silva et al (2014) evaluated the adaptability of dairy goats with aid of thermographic precision in the Brazilian semi-arid region, finding BGHI averages (in the sun) of 86.90 in afternoon shift.
The above authors did not consider a danger situation to animals, mainly because they maintain the rectal temperature within the established average for the species.

Analysis of variance showed day shift effect $(\mathrm{P}<0.05)$ on all physiological variables, with highest mean values observed in afternoon shift (Figure 2). There is increase of $31.5 \%, 16.2 \%$ and $1.7 \%$ in the respiratory rate, heart rate (HR) and rectal temperature, respectively, in afternoon shift, compared to morning shift.

RR averages in the morning shift were 32.68 breaths/min and in afternoon shift of 43.00 breaths/min. This superiority in afternoon shift in relation to morning shift indicates that the animals presented greater difficulty in maintaining the thermal equilibrium with the environment, being necessary the increase of RR to maintain the normal RT.

Furtado and Crispim (2015) stated that, in general, RR of goats submitted to hot environments are high, a fact justified by animals trying to dissipate heat to the environment. Silva et al (2006) evaluated the physiological parameters of goats in the semi-arid region of Paraíba state (Brazil), the authors observed that the RR increased significantly $(\mathrm{P}<0.05) 63.37 \%$ in afternoon shift in relation to the morning shift and justified that the increase this parameter is associated with the increase of environmental variables. However, although observed high temperatures, the studied goats (undefined racial pattern), showed a high degree of adaptation.

Leite et al (2012), when evaluating the influence of bioclimatic factors on the productive and physiological indices of native goats, found averages of 35.6 and 50.8 breaths/min for the RR variable at 9:00 and 15:00 hours, respectively. These averages are close to those found in the present study for the morning and afternoon shifts. The authors also reported that muscle work, ambient temperature, feed intake, age and body size are some of the factors responsible for the variation in $\mathrm{RR}$.

The HR variable was elevated in both day shifts, presenting averages of 94.12 and 109.46 beats/min for the morning and afternoon shifts, respectively. These values exceeded the reference values for goats, which according to Kelly (1976), range from 70 to 90 beats/min. It is worth noting that in high temperature environments, such as the region where our study was conducted, in which heat generation is greater than the heat dissipation, all sources that generate endogenous heat are inhibited, such as feed intake, while the physiological responses increase.

It can be seen that RT variable presented averages of $38.96{ }^{\circ} \mathrm{C}$ in the morning shift and $39.65{ }^{\circ} \mathrm{C}$ in the afternoon shift (Figure 2). The superiority of the RT observed in afternoon shift may probably be explained by increase in the additional thermal load received from solar radiation, resulting in increase in the amount of internal heat of the animals. It is noteworthy that, once there was an increase in 
the amount of internal heat of the animals. They activated their physiological variables, such as RR, as a means of heat dissipating and keep youself inside of the thermoneutrality zone.

Mousinho et al (2014) assessed physiological parameters of goats in Teresina, Piauí state (Brazil), and found in the gilts a RT mean of $38.78{ }^{\circ} \mathrm{C}$. In this same dry and hot period of the year, this authors found TA mean of $39.9 \pm 1.9^{\circ} \mathrm{C}$ and $22.8 \pm 9.2 \%$ for the UA, both in the afternoon shift. The authors still observed a RR mean of 43.22, suggesting that they used this mecanism to adjust to the environmental conditions to which they were subjected.

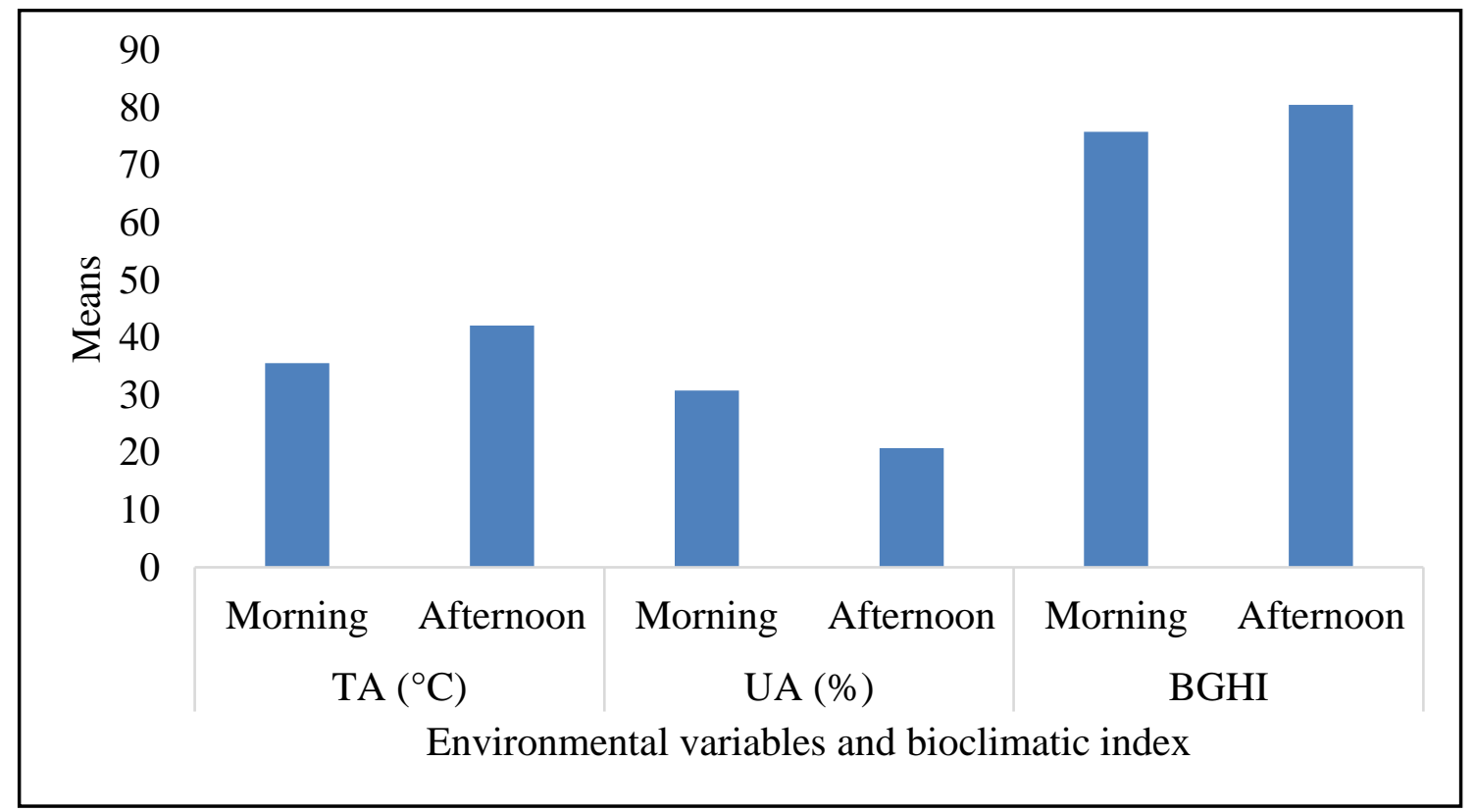

Figure 1 Mean values of air temperature (TA), relative humidity (UA) and black globe-humidity index (BGHI).

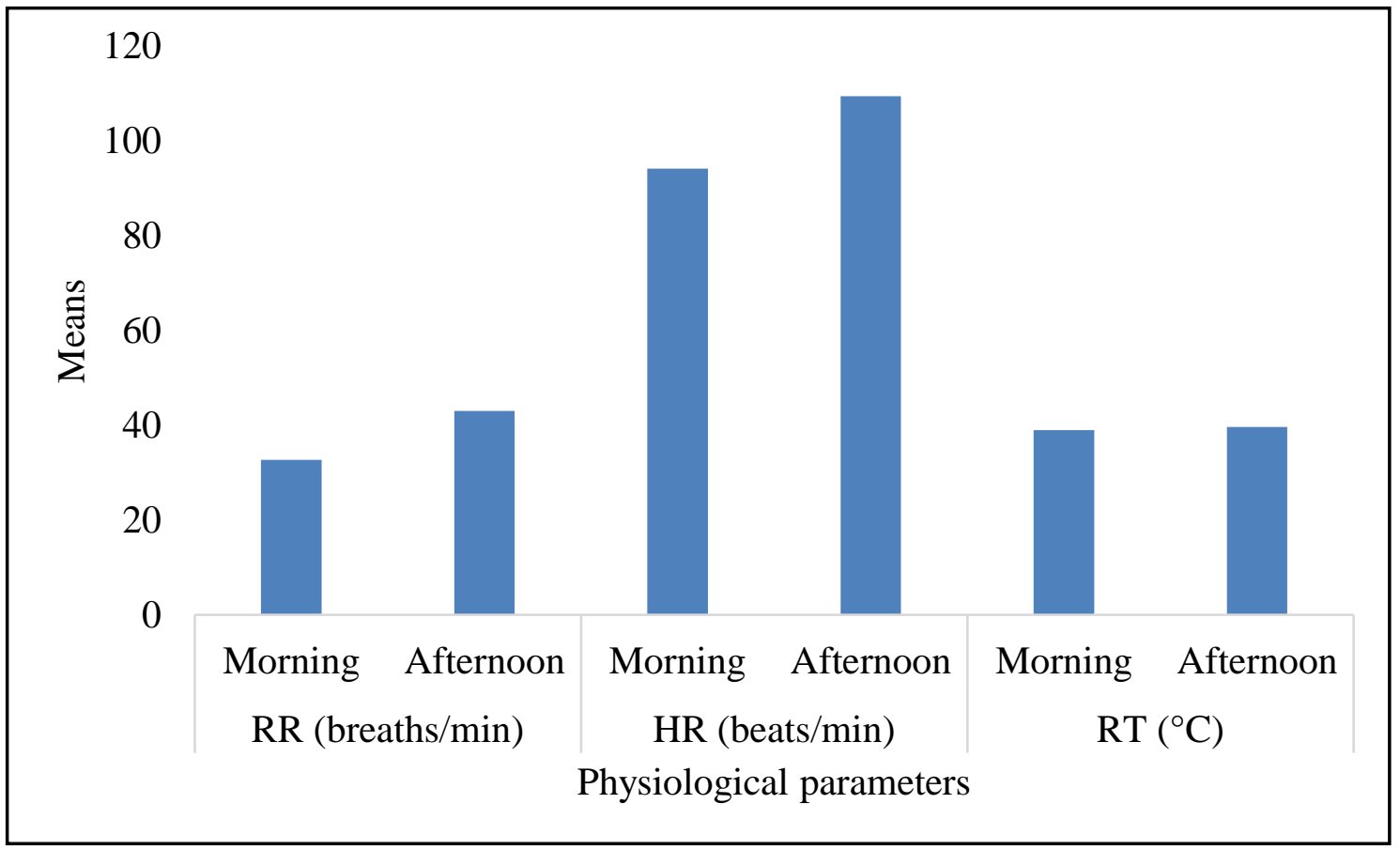

Figure 2 Mean values of respiratory rate (RR), heart rate (HR) and rectal temperature (RT) of young goats bred in an extensive system.

In compiling information about the heat stress effect on milk production of goats, Fonseca et al (2016) reported that normal RT in goats varies from 38.5 to $39.7^{\circ} \mathrm{C}$, corroborating with the values found in the present study. The authors also 
pointed out that factors such as day shift and season may cause changes in the physiological parameters of the animals, resulting in possible productive and reproductive losses in the herd. Thus, it is necessary to adopt technologies and management strategies that promote the proper exploitation of animals, minimizing the negative effects of heat stress, in order to guarantee a greater quantity and quality of the final product.

\section{Conclusions}

The animals activated the respiratory and heart rate during the day shifts to maintain rectal temperature within the limits considered normal for this species, suggesting a possible adaptation of these animals to regions of tropical climate.

\section{References}

Araújo JIM, Araújo AC, Rodrigues HTM, Oliveira LG, Barros Junior CP, Fonseca, WJL, Luz CSM, Sousa Júnior SC (2016) Effect of different climatic environments on physiological characteristics of crossbred calves (Holandês x Gyr). Revista de Ciências Agroveterinária 15:259-265.

Fonseca WJL, Azêvedo DMMR, Campelo JEG, Fonseca WL, Luz CSM, Oliveira MRA, Evangelista AF, Borges LS, Sousa Jr (2016) Effect of heat stress on milk production of goats from Alpine and Saanen breeds in Brazil. Archivos de Zootecnia 65:615-621.

Furtado GD, Crispim MC (2015) On-pasture performance evaluation of Saanem and Parda Alpina goats, in Brazilian semi-arid areas, as contribution to the understanding of global warming impact. Gaia Scientia 9:28-36.

IBGE (2016). Instituto Brasileiro de Geografia e Estatística. Pesquisa Pecuária Municipal.https://g1.globo.com/bahia/noticia/municipiosda-ba-tem-os-maiores-numeros-de-caprinos-ovinos-e-alevinos-dopais-aponta-ibge.ghtml. Acessado em 12 de janeiro de 2018.

Kawadata CY, Castro RC, Savastano Júnior H (2005) Thermal comfort indexes and physiological responses of Holstein calves in individual houses with different roofings. Revista Engenharia Agrícola 25:598-607.

Kelly WR (1976) Diagnóstico clínico veterinário. 2ed. Barcelona: Continetal, 1976, 444p.

Leite JRS, Furtado DA, Leal AF, Souza BB, Silva AS (2012) Thermal comfort parameters of native goats raised in confinement in the semiarid of Paraíba state. Revista Brasileira de Engenharia Agrícola e Ambiental 16:443-448.

Lima LR, Barbosa Filho JAD (2013) Impact of pre-slaughter management on the welfare of goats and sheep. Journal of Animal Behaviour and Biometeorology 1:52-60.

Mousinho LRB, Campêlo JEG, Sousa Jr CS, Azevêdo DMMR, Leal TM, Moura RMAS (2014) Physiological responses of Anglo Nubian female goats in the environmental conditions with high temperature. Revista Brasileira de Saúde e Produção Animal 15:160-171.

R Core Team (2016) R: A language and environment for statistical computing. Vienna: R Foundation for Statistical Computing.
Silva CMBA, Souza BB, Brandão PA, Marinho PVT, Benício TMA (2011) Effect of the semiarid climatic conditions on the physiological behavior of saanen x boer crossbred goats. Revista Caatinga 24:195199.

Silva EMN, Souza BB, Silva GA, Alcântara MDB, Cunha MGG, Marques BAA (2014) Avaluation of the adaptability of dairy goats with help of thermographic precision in the semiarid brazilian. Revista Brasileira de Medicina Veterinária 36:231-237.

Silva GA, Souza BB, Alfaro CEP, Silva EMN, Azevedo SA, Azevedo Neto J, Silva RMN (2006) Effect of year time and period of day on physiological parameters of reproductive goats in the semiarid Paraiba. Revista Brasileira de Engenharia Agrícola e Ambiental 10:903-909.

Souza FC, Tinôco IFF, Baêta FC (2002) Avaliação de materiais alternativos para confecção do termômetro de globo. Revista Ciência e Agrotecnologia 26:157-164. 